\title{
Short-term and long-term response to pulmonary exacerbation treatment in cystic fibrosis
}

\author{
Sonya L Heltshe, ${ }_{1}^{1,2}$ Christopher H Goss, ${ }^{1,3}$ Valeria Thompson, ${ }^{1}$ Scott D Sagel, ${ }^{4}$ \\ Don B Sanders, ${ }^{5}$ Bruce C Marshall, ${ }^{6}$ Patrick A Flume ${ }^{7}$
}

\begin{abstract}
- Additional material is published online only. To view please visit the journal online (http://dx.doi.org/10.1136/ thoraxjn-2014-206750)

For numbered affiliations see end of article.

Correspondence to Dr Sonya L Heltshe, Seattle Children's Research Institute M/S CW8-5B, 2001 Eighth Ave, Suite 400 , Seattle, WA 98121, USA; sonya.heltshe@ seattlechildrens.org
\end{abstract}

Received 24 December 2014 Revised 23 March 2015 Accepted 2 April 2015 Published Online First 24 April 2015

\section{SLinked}

- http://dx.doi.org/10.1136/ thoraxjnl-2014-206710

\section{CrossMark}

To cite: Heltshe SL, Goss CH, Thompson V, et al. Thorax 2016;71:223-229.

\section{ABSTRACT}

Background Treatment of pulmonary exacerbations

(PEx) in cystic fibrosis (CF) varies widely with no

consensus on management practices or best indicators of therapeutic success. To design trials evaluating PEx treatment factors, we characterise the heterogeneity of PEx care in adults and paediatrics, and correlate it with measures of clinical response including short-term and long-term lung function changes, change in symptom severity score and time to next intravenous antibiotic therapy.

Methods Data were used from a prospective observational study of patients with CF $\geq 10$ years of age enrolled at six sites between 2007 and 2010. All were started on intravenous antibiotics for a clinically diagnosed PEx. Analysis of variance, logistic and Cox regression were used to examine the association of treatment factors with short-term and long-term clinical response.

Results of 123 patients with CF $(60 \%$ women, aged $23.1 \pm 10.2$ years), $33 \%$ experienced $<10 \%$ relative improvement in $\mathrm{FEV}_{1}$ during treatment, which was associated with failing to recover baseline lung function 3 months after treatment $(\mathrm{OR}=7.8,95 \% \mathrm{Cl} 1.9$ to 31.6 , $\mathrm{p}=0.004$ ) and a longer time to next intravenous antibiotic ( $\mathrm{HR}=0.48,95 \% \mathrm{Cl} 0.27$ to $0.85, \mathrm{p}=0.011$ ). Symptom improvement was observed but was not associated with subsequent lung function or time to next antibiotic therapy, which had a median recurrence time of 143 days.

Conclusions Immediate symptomatic or respiratory response to PEx treatment did not have a clear relationship with subsequent outcomes such as lung function or intravenous antibiotic-free interval. These results can inform future research of treatment regimens for PEx in terms of interventions and outcome measures. Trial registration NCT00788359 (www.clinicaltrials. gov).

\section{INTRODUCTION}

Infection, inflammation and structural damage of the lung are characteristic of cystic fibrosis (CF). Daily symptoms of chronic infection are punctuated with acute episodes of increased cough, fatigue, physical findings and other signs including rapid drop in lung function called a pulmonary exacerbation (PEx). Such events are associated with mortality, ${ }^{12}$ reduced quality of life, ${ }^{3}$ unrecoverable loss of lung function ${ }^{2} 4$ and increased healthcare costs. ${ }^{5}$ There were $>15000 \mathrm{PEx}$ recorded in the CF Foundation (CFF) National Patient Registry (NPR)

\section{Key messages}

What is the key question?

- How do varying treatments for pulmonary exacerbation (PEx) in cystic fibrosis (CF) correspond with clinical response, including symptom severity, short-term and long-term lung function, and time to next PEx?

\section{What is the bottom line?}

- Across multiple centres, the patient clinical characteristics and treatment factors that are associated with short-term clinical improvement differ from those associated with subsequent lung function recovery and time to next acute event treated with intravenous antibiotics.

\section{Why read on?}

- This is the only multicentre evaluation of clinically defined PEx in both paediatric and adult CF patients to examine a comprehensive set of clinical responses for determining an outcome measure for future studies of exacerbation therapies.

in 2012, affecting nearly $40 \%$ of patients with CF at least once. ${ }^{6}$ Treatment for PEx varies across patients and centres, ${ }^{7}$ but often includes a combination of intravenous, inhaled or oral antibiotics ${ }^{8}$ in conjunction with increased airway clearance therapy, inhaled mucolytics or corticosteroids. Location (inpatient or outpatient) and duration of therapy may differ by factors such as patient gender, ${ }^{9} 10$ age, ${ }^{11}$ PEx history, disease severity, microbiology, physician goals and patient preferences. ${ }^{12}$

Recent guidelines cite scarce evidence to support common treatment regimens for PEx management, ${ }^{13}$ highlighting the need for research in this area. While studies have examined different shortterm $^{14-16}$ and long-term ${ }^{4} 1718$ outcomes of PEx, and factors associated with them, there is no consensus on the most relevant or useful measure of PEx management success or failure.

Physicians generally treat to alleviate signs and symptoms or recover lost lung function, ${ }^{19}$ but little is understood about the implications of failing to achieve those immediate goals in patients with CF. To inform clinical care and research aimed at improving PEx treatment regimens, we analysed data from a multicentre, prospective study of PEx 
to characterise the heterogeneity of treatment factors and correlate them with measures of clinical response, including symptom severity, short-term and long-term lung function, and time to next PEx. Specifically, we aimed to determine the association between immediate symptom and lung function response with subsequent need for intravenous antibiotics and ultimate pulmonary function recovery.

\section{MATERIALS AND METHODS}

\section{Patients and study design}

Patients with CF 10 years and older being started on two or more intravenous antibiotics for a clinically diagnosed PEx using criteria outlined by a CFF Consensus Conference ${ }^{20}$ were eligible to enrol in the observational study conducted at six adult and paediatric CF centres between 2007 and $2010 .^{21}$ Study protocol encouraged at least 10 days of antibiotic administration and mucus clearance in accordance with CF Care Guidelines, ${ }^{13}$ but all other treating factors, including location, concomitant administration of inhaled or oral antibiotics or systemic steroids, were at physician's discretion. Spirometry ${ }^{22}$ and sputum cultures were performed at time of enrolment (within $24 \mathrm{~h}$ of intravenous initiation) and approximately $10-14$ days later. $\left(\mathrm{FEV}_{1}\right)$ per cent predicted of normal was calculated. ${ }^{23}{ }^{24}$ Participants completed the CF Respiratory Symptom Diary (CFRSD) ${ }^{25}$ for each day up to 21 days.

\section{Variables and outcomes}

The diagnosis of PEx was made by clinician but verified with a scoring algorithm (score excluding change in $\mathrm{FEV}_{1}$ at admission $\geq 2.6$ ). ${ }^{26}$ Short-term outcomes are those that occur during treatment of the PEx or within 30 days of completion: lung function nonresponse to treatment was categorised as $<10 \%$ relative improvement in $\mathrm{FEV}_{1}$ (L) from enrolment visit (intravenous antibiotic initiation) to follow-up visit 10-14 days later-within 10 days of end of intravenous therapy. This represents 'immediate response ${ }^{11}$ regardless of a patient's 'baseline' or 'sick decline', and is calculated as a relative change to account for $\mathrm{FEV}_{1}$ at the time of admission. The Chronic Respiratory Infection Symptom Score was applied to the CFRSD to calculate a severity score from 0 to 100 (100 being most severe). ${ }^{27}$ Change in symptom score was calculated from enrolment visit to end of intravenous therapy or last completed CFRSD (up to 21 days after intravenous initiation), whichever came first.

Study data were merged with CFFNPR to determine other clinical factors including: CF-related diabetes (CFRD), respiratory microbiology, best $\mathrm{FEV}_{1}$ per cent predicted in the preceding 6 months and history of intravenous antibiotic episodes in the preceding 6 months. Interim clinical outcomes (those occurring within 3 months of PEx treatment completion) and longterm outcomes (those occurring $>3$ months after intravenous treatment) were also obtained from the CFFNPR. Best FEV 1 per cent predicted in the 3 months following study PEx treatment was ascertained to determine $90 \%$ recovery of best $\mathrm{FEV}_{1}$ from 6 months prior ${ }^{4}$ and represents 'baseline recovery'. Time to next intravenous antibiotic episode (initiated $\geq 7$ days after end of intravenous therapy for study PEx) was calculated and censored at the time of last encounter.

\section{Statistical analyses}

Summaries including mean and SD are reported for treatment factors and clinical outcomes by age group ( $<18$ or $\geq 18$ years), $t$ tests and Fisher's exact test compare age groups. Analysis of variance, logistic and Cox regression were used to explore the association of clinical characteristics and treatment factors with symptom response and $\mathrm{FEV}_{1}$ change $<10 \%$ during intravenous antibiotic treatment, recovery of pre-PEx $\mathrm{FEV}_{1}{ }^{4}$ and time to next intravenous antibiotic episode. Backward selection with significance level 0.30 to remain in model was applied to eliminate covariates from the full model, which included women, age $\geq 18$ years, CFRD, Pseudomonas aeruginosa-positive, methicillinresistant Staphylococcus aureus (MRSA)-positive, $\mathrm{FEV}_{1}$ per cent predicted $<50 \%$ at PEx start, $10 \%$ drop in $\mathrm{FEV}_{1}$ per cent predicted at initiation of study PEx treatment ('sick decline'), steroid use, oral or inhaled antibiotic use for PEx treatment, MRSA active drug for PEx treatment (doxycycline, linezolid, minocycline, rifampin, tigecycline, vancomycin or trimethoprim/sulfamethoxazole), duration of intravenous antibiotics ( $<10$ days, 10 14 days or $>14$ days) and history of intravenous antibiotics in the preceding 6 months. A relaxed 0.30 criterion was used to allow non-significant covariates in the model that stabilise estimates of other parameters. $^{28}$ Immediate lung function non-response $\left(<10 \%\right.$ relative improvement in $\mathrm{FEV}_{1}(\mathrm{~L})$ during treatment) and change in symptom score ${ }^{27}$ were then added to the models for (1) failure to recover baseline $\mathrm{FEV}_{1}$ (2) time to next intravenous antibiotic. Model coefficient estimates including OR and HRs are reported with 95\% CIs. Reported p values are two-sided and considered exploratory; no adjustments were made for multiple comparisons. No sample size estimates were performed. Analyses were performed using SAS (V.9.2, SAS Institute, Cary, North Carolina, USA, 2009), and R (V.2.15, The R Foundation for Statistical Computing, Vienna, Austria, 2012).

\section{RESULTS}

A total of 123 patients with CF (60.2\% women) were treated with intravenous antibiotics for a diagnosed PEx (table 1). Average age was 23.1 years $(S D=10.2)$ and $F_{1}$ per cent predicted $(\%)$ at admission was 55.8\% $(\mathrm{SD}=20.9)$. Patients with paediatrics (10-17 years old) made up 35\% $(n=43)$ of the cohort, and best $\mathrm{FEV}_{1}$ in 6 months prior was on average (SD) $83.1 \%(18.3)$ in children and 53.2\% (19.7) in adults. $P$. aeruginosa was more prevalent in adults $(75.0 \%$ vs $44.2 \%, \mathrm{p}=0.001)$, while methicillin-sensitive Staphylococcus aureus (MSSA) $(28.8 \%$ vs $27.9 \%, \mathrm{p}=0.9)$ and MRSA $(28.8 \%$ vs $39.5 \%$, $\mathrm{p}=0.23$ ) were similar in adults and children.

\section{PEx treatment}

PEx treatment features are in table 2 by age. None of the patients with paediatrics were treated exclusively at home, and adults were treated on average 4.2 days longer than those under 18 years $(95 \%$ CI 1.5 to $6.9, \mathrm{p}=0.003)$. Intravenous tobramycin was the most commonly prescribed antibiotic in combination; paediatric patients were more likely to get a MRSA active antibiotic $(65.1 \%$ vs $45.0 \%, \mathrm{p}=0.039)$, and $16.3 \%$ overall received systemic corticosteroids.

\section{PEx outcomes}

Online supplementary figure S1 shows enrolment and follow-up for each of the outcomes. Table 3 summarises short-term and long-term clinical outcomes by age group. Among the 102 participants with spirometry at enrolment and at or near the end of intravenous antibiotic treatment, $73 \%$ had lung function measured within \pm 2 days of intravenous end, 93\% were within a week; two had PFTs not within 10 days of intravenous end and were removed from the calculations. There was marked improvement in immediate $\mathrm{FEV}_{1}$ response in the younger patients $(5.9 \%$ predicted more than adults, 95\% CI 2.3 to 9.5 , $\mathrm{p}=0.002$ ) (figure 1), while both age groups had similar response in symptom severity, baseline $\mathrm{FEV}_{1}$ recovery in subsequent 3 months and intravenous antibiotic need (by 30, 90 and 
Table 1 Demographics and baseline characteristics

\begin{tabular}{|c|c|c|}
\hline & \multicolumn{2}{|c|}{$\begin{array}{l}\text { Study participants } \\
(\mathrm{N}=123)\end{array}$} \\
\hline & $\mathbf{N}$ & Per cent \\
\hline Sex, female & 74 & 60.2 \\
\hline \multicolumn{3}{|l|}{ Race } \\
\hline Caucasian & 114 & 92.7 \\
\hline Hispanic & 3 & 2.4 \\
\hline African-American & 4 & 3.3 \\
\hline Asian & 1 & 0.8 \\
\hline Pacific Islander & 1 & 0.8 \\
\hline \multicolumn{3}{|l|}{ Genotype } \\
\hline Delta F508 homozygous & 67 & 54.5 \\
\hline Delta F508 heterozygous & 45 & 36.6 \\
\hline Other/unknown/not genotyped & 11 & 8.9 \\
\hline Pancreatic insufficient ${ }^{*}$ & 117 & 95.1 \\
\hline \multicolumn{3}{|l|}{ Age group (years) } \\
\hline 10-17 & 43 & 35.0 \\
\hline$\geq 18$ & 80 & 65.0 \\
\hline \multicolumn{3}{|l|}{$\mathrm{FEV}_{1} \%$ predicted $t$} \\
\hline$<50$ & 49 & 39.8 \\
\hline $50-69$ & 34 & 27.6 \\
\hline $70-89$ & 26 & 21.1 \\
\hline$\geq 90$ & 7 & 5.7 \\
\hline $\mathrm{FEV}_{1}$ drop $\geq 10 \%$ predicted presenting for PEx & 66 & 53.7 \\
\hline Intravenous antibiotic for PEx in 6 months prior§ & 51 & 41.5 \\
\hline \multicolumn{3}{|l|}{ Microbiologyף } \\
\hline Pseudomonas aeruginosa & 79 & 64.2 \\
\hline MSSA & 34 & 27.6 \\
\hline MRSA & 40 & 32.5 \\
\hline Burkolderia cepacia & 4 & 3.3 \\
\hline Stenotrophomonas maltophilia & 15 & 12.2 \\
\hline Achromobacter xylosoxidans & 11 & 8.9 \\
\hline Haemophilus influenza & 4 & 3.3 \\
\hline Aspergillus & 9 & 7.3 \\
\hline \multirow[t]{2}{*}{ CF-related diabetes } & 37 & 30.1 \\
\hline & Mean & SD \\
\hline Age (years) & 23.1 & 10.2 \\
\hline Body mass index $\left(\mathrm{kg} / \mathrm{m}^{2}\right)$ & 19.9 & 3.4 \\
\hline $\mathrm{FEV}_{1} \%$ predicted at enrolment $\dagger$ & 55.8 & 20.9 \\
\hline $\mathrm{FEV}_{1} \%$ best in 6 months prior to visit $1^{* *}$ & 63.7 & 23.9 \\
\hline \multicolumn{3}{|c|}{$\begin{array}{l}\text { *Evidence of pancreatic enzyme use. } \\
\text { †Spirometry \% predicted is calculated using the Wang equations }{ }^{24} \text { for females } \\
<16 \text { years of age and males }<18 \text { years of age. The Hankinson equations }{ }^{23} \text { are used } \\
\text { for females } 16 \text { years and older, males } 18 \text { years and older. } \\
\text { ‡As reported as criterion on pulmonary exacerbation diagnostic form. } \\
\text { \$One or more episodes of intravenous antibiotic for reason 'pulmonary exacerbation' } \\
\text { recorded in the CFF Registry in } 6 \text { months prior to study PEx. } \\
\text { TAmong respiratory cultures isolated at time of enrolment ( } \mathrm{n}=107) \text { or in CFF registry } \\
\text { in } 6 \text { months prior to enrolment ( } \mathrm{n}=16 \text { ). } \\
\text { **Best of all spirometry in CFF Registry in } 6 \text { months prior to study PEx. } \\
\text { CF, cystic fibrosis; CFF, CF Foundation; MRSA, methicillin-resistant Staphylococcus } \\
\text { aureus; MSSA, methicillin-sensitive Staphylococcus aureus; PEx, pulmonary } \\
\text { exacerbation. }\end{array}$} \\
\hline
\end{tabular}

180 days) after treatment for study PEx. The Kaplan-Meier curves (figure 2) for time to next intravenous antibiotic did not significantly differ by age group $(p=0.74)$.

\section{Association of demographic, clinical and treatment factors with outcomes}

Figure 3 shows the association of clinical and treatment factors with each of the clinical responses $(p<0.30)$. MRSA was
Table 2 Pulmonary exacerbation treatment by age group

\begin{tabular}{|c|c|c|c|}
\hline & \multicolumn{2}{|l|}{ Age group } & \multirow[b]{2}{*}{$\begin{array}{l}\text { All } \\
N=123\end{array}$} \\
\hline & $\begin{array}{l}<18 \text { years } \\
\mathrm{N}=43\end{array}$ & $\begin{array}{l}\geq 18 \text { years } \\
\mathrm{N}=80\end{array}$ & \\
\hline \multicolumn{4}{|c|}{ Duration of intravenous antibiotics } \\
\hline $\begin{array}{l}\text { Mean (SD) } \\
\mathrm{n}(\%)\end{array}$ & $14.0(5.6)$ & $18.2(9.8)$ & $16.7(8.8)$ \\
\hline $0-10$ days & $11(25.6)$ & $9(11.3)$ & $20(16.3)$ \\
\hline$>10-14$ days & $21(48.8)$ & $26(32.5)$ & $47(38.2)$ \\
\hline$>14-21$ days & $8(18.6)$ & $31(38.8)$ & $39(31.7)$ \\
\hline$>21$ days & $3(7.0)$ & $14(17.5)$ & $17(13.8)$ \\
\hline \multicolumn{4}{|l|}{$\begin{array}{l}\text { Location of treatment } \\
\qquad \mathrm{n}(\%)\end{array}$} \\
\hline Exclusively hospital & $28(65.1)$ & $35(43.8)$ & $63(51.2)$ \\
\hline Exclusively home & $0(0)$ & $21(26.3)$ & $21(17.1)$ \\
\hline Both hospital and home & $13(30.2)$ & $23(28.8)$ & $36(29.3)$ \\
\hline Unknown & $2(4.7)$ & $1(1.3)$ & $3(2.4)$ \\
\hline \multicolumn{4}{|c|}{$\begin{array}{l}\text { Number of intravenous antibiotics } \\
\mathrm{n}(\%)\end{array}$} \\
\hline 1 & $1(2.3)$ & $1(1.3)$ & $2(1.6)$ \\
\hline 2 & $23(53.5)$ & $46(57.5)$ & $69(56.1)$ \\
\hline 3 & $16(37.2)$ & $25(31.3)$ & $41(33.3)$ \\
\hline $4+$ & $3(7.0)$ & $8(10.0)$ & $11(8.9)$ \\
\hline \multicolumn{4}{|c|}{$\begin{array}{l}\text { Most common intravenous antibiotics } \\
\mathrm{n}(\%)\end{array}$} \\
\hline Tobramycin & $22(51.2)$ & $54(67.5)$ & $76(61.8)$ \\
\hline Meropenem & $12(27.9)$ & $45(56.3)$ & $57(46.3)$ \\
\hline Ceftazidime & 7 (16.3) & $27(33.8)$ & $34(27.6)$ \\
\hline Vancomycin & $18(41.9)$ & $11(13.8)$ & $29(23.6)$ \\
\hline Cefepime & $11(25.6)$ & $12(15.0)$ & $23(18.7)$ \\
\hline \multicolumn{4}{|l|}{ MRSA* active drug } \\
\hline $\mathrm{n}(\%)$ & $28(65.1)$ & $36(45.0)$ & $64(53.0)$ \\
\hline \multicolumn{4}{|l|}{ Inhaled antibiotics } \\
\hline$n(\%)$ & $5(11.6)$ & $7(8.8)$ & $12(9.8)$ \\
\hline \multicolumn{4}{|l|}{ Oral antibiotics } \\
\hline $\mathrm{n}(\%)$ & $5(11.6)$ & $22(27.5)$ & $27(22.0)$ \\
\hline \multicolumn{4}{|l|}{ Steroids } \\
\hline $\mathrm{n}(\%)$ & $7(16.3)$ & $13(16.3)$ & $20(16.3)$ \\
\hline
\end{tabular}

*Received any of doxycycline, linezolid, minocycline, rifampin, tigecycline, trimethoprim/sulfamethoxazole or vancomycin.

MRSA, methicillin-resistant Staphylococcus aureus.

associated with a diminished symptom severity reduction (average 8.8 point increase, 95\% CI 1.8 to $15.8, \mathrm{p}=0.015$ ), while treatment choices such as steroids $(-12.0$ points, $95 \% \mathrm{CI}$ -19.7 to $-4.3, \mathrm{p}$ value $=0.003$ ), oral/inhaled antibiotics and MRSA active drugs were associated with larger reductions in symptom severity. Longer treatment durations (10-14 days and $>14$ days as compared to $<10$ days) were associated with less symptom improvement but not statistically significant.

Immediate $\mathrm{FEV}_{1}$ non-response was associated with use of oral/inhaled antibiotics $(\mathrm{OR}=3.5,95 \%$ CI 1.2 to 10.6, $\mathrm{p}=0.027)$ and longer treatment duration ( $>14$ days compared with $<10$ days, $\mathrm{p}=0.021$ ), whereas a drop of $10 \% \mathrm{FEV}_{1}$ at admission had a protective effect and was associated with a reduced odds of failure to recover ( $\mathrm{OR}=0.30,95 \% \mathrm{CI} 0.11$ to $0.81, \mathrm{p}=0.017)$. CFRD was the only covariate with a common, though weak, association with both immediate $\mathrm{FEV}_{1}$ response $(p=0.221)$ and recovery of baseline $\mathrm{FEV}_{1}(\mathrm{p}=0.257)$. History of intravenous antibiotics was the only factor significantly associated $(\mathrm{OR}=4.8,95 \% \mathrm{CI} 1.2$ to $18.4, \mathrm{p}=0.023)$ with nonrecovery of baseline $\mathrm{FEV}_{1}$ post treatment. 
Table 3 Clinical response by age group and overall

\begin{tabular}{|c|c|c|c|}
\hline & \multicolumn{2}{|l|}{ Age group } & \multirow[b]{2}{*}{$\begin{array}{l}\text { Total } \\
\mathrm{N}=123\end{array}$} \\
\hline & $\begin{array}{l}<18 \\
\mathrm{~N}=43\end{array}$ & $\begin{array}{l}\geq 18 \\
\mathrm{~N}=80\end{array}$ & \\
\hline \multicolumn{4}{|c|}{ Short-term treatment response } \\
\hline \multicolumn{4}{|c|}{ Improvement in symptom score* } \\
\hline $\mathrm{n}$ & 36 & 57 & 93 \\
\hline Mean (SD) & $-21.7(13.9)$ & $-22.2(14.9)$ & $-22.0(14.4)$ \\
\hline \multicolumn{4}{|c|}{ Change in $\mathrm{FEV}_{1}(\%$ predicted $) \dagger$} \\
\hline $\mathrm{n}$ & 35 & 65 & 100 \\
\hline Mean (SD) & $13.9(9.2)$ & $8.0(8.3)$ & $10.0(9.1)$ \\
\hline \multicolumn{4}{|c|}{$<10 \%$ improvement $\mathrm{FEV}_{1}(\mathrm{~L}) \ddagger$} \\
\hline $\mathrm{n}(\%)$ & $10(28.6)$ & $23(35.4)$ & $33(33.0)$ \\
\hline \multicolumn{4}{|c|}{ Intravenous antibiotic within 30 days of completing intravenous for study PEx§ } \\
\hline $\mathrm{n}(\%)$ & $2(4.7)$ & $9(11.3)$ & $11(8.9)$ \\
\hline \multicolumn{4}{|c|}{ Interim response: 3 months post-study PEx } \\
\hline \multicolumn{4}{|c|}{ Change in best $\mathrm{FEV}_{1}$ (\% predicted) from 6 months prior to 3 months post PEx } \\
\hline $\mathrm{n}$ & 37 & 71 & 108 \\
\hline Mean (SD) & $1.6(12.4)$ & $2.5(7.9)$ & $2.2(9.6)$ \\
\hline \multicolumn{4}{|c|}{$<90 \% \mathrm{FEV}_{1}$ baseline recovery } \\
\hline n $(\%)$ & $5(13.5)$ & $8(11.3)$ & $13(12.0)$ \\
\hline \multicolumn{4}{|c|}{ Intravenous antibiotic within 90 days of completing intravenous for study PEx§ } \\
\hline $\mathrm{n}(\%)$ & $10(23.3)$ & $30(37.5)$ & $40(32.5)$ \\
\hline \multicolumn{4}{|c|}{ Long-term response } \\
\hline \multicolumn{4}{|c|}{ Intravenous antibiotic within 180 days of completing Intravenous for study PEx } \\
\hline n (\%) & $23(53.5)$ & $48(60.0)$ & $71(57.7)$ \\
\hline \multicolumn{4}{|c|}{ Time to next intravenous antibiotic§ (days) } \\
\hline Mean (SD) & $236.5(190.3)$ & $234.7(235.9)$ & $235.3(220.2)$ \\
\hline Median & 174.0 & 139.0 & 143.0 \\
\hline Min, Max & $22.0,740.0$ & $10.0,984.0$ & $10.0,984.0$ \\
\hline
\end{tabular}

The hazard of subsequent intravenous antibiotic was significantly increased by history of intravenous episodes $(\mathrm{HR}=2.7$, 95\% CI 1.8 to $4.1, \mathrm{p}<0.001$ ) and low $\mathrm{FEV}_{1}$ at admission

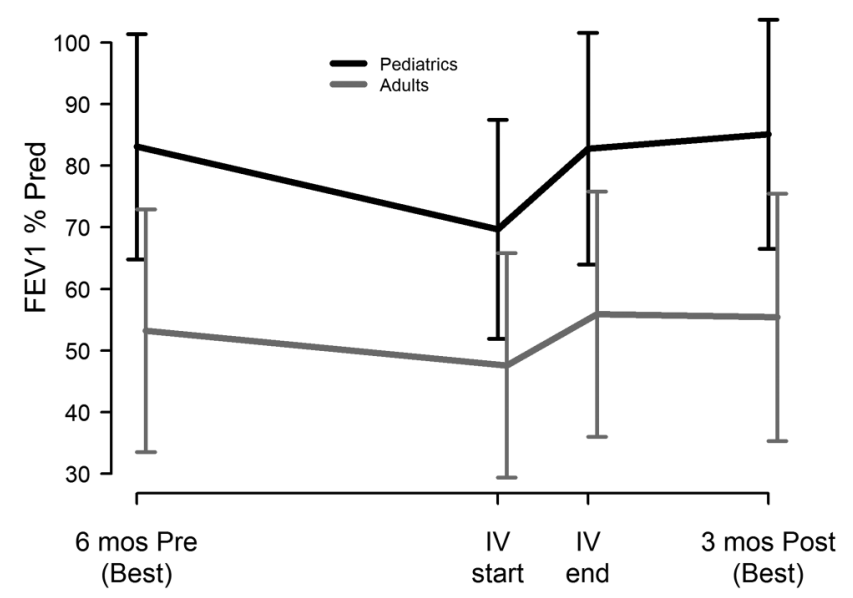

Figure 1 Lung function by age group. $\mathrm{FEV}_{1} \%$ of predicted mean $\pm 1 \mathrm{SD}$ for paediatric participants (black lines, $n=37$ ) and adult participants (gray lines, $n=71$ ): best during 6 months (mos) before study pulmonary exacerbations (PEx), at time of intravenous (IV) initiation for PEx, at end of intravenous for PEx and best during 3 months after study PEx.
$(\mathrm{HR}=2.4,95 \%$ CI 1.5 to $3.9, \mathrm{p}<0.001)$, whereas longer treatment duration was associated with a reduced time to next exacerbation (10-14 days: $\mathrm{HR}=0.50,95 \%$ CI 0.29 to 0.889 , $\mathrm{p}=0.018 ;>14$ days: $\mathrm{HR}=0.38,95 \%$ CI 0.20 to $0.70, \mathrm{p}$ $=0.002)$.

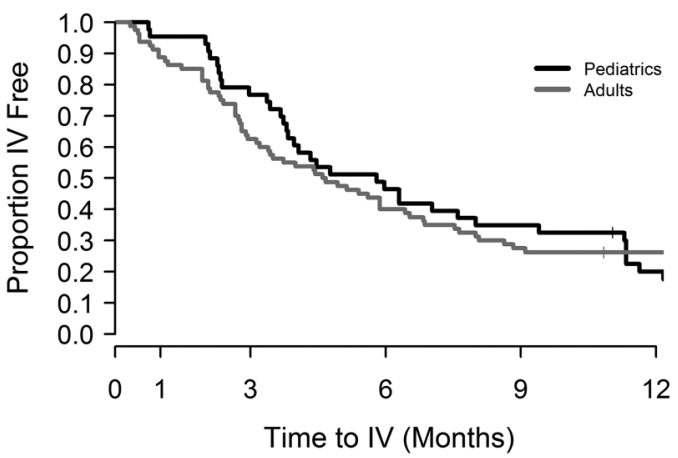

Figure 2 Kaplan-Meier survival curves for time to next intravenous antibiotic episode by age group. Proportion intravenous antibiotic free by time (after study pulmonary exacerbations) in paediatric (black lines, $\mathrm{n}=43$ ) and adult participants (gray lines, $n=80$ ). 


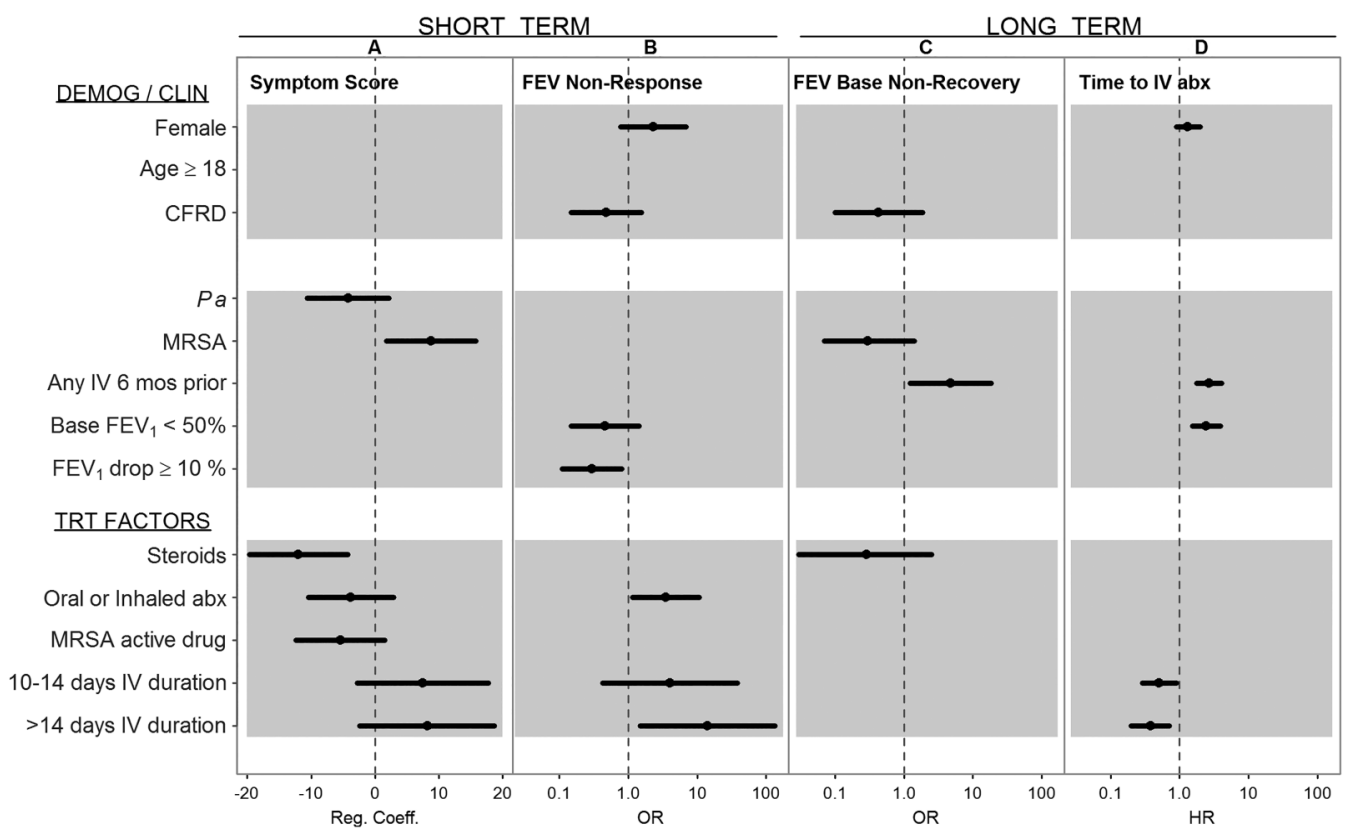

Figure 3 Factors associated with short-term and long-term outcomes of pulmonary exacerbations (PEx) treatment. (A) Multivariate regression coefficients (Reg. Coeff) and 95\% Cls for demographic (DEMOG), clinical (CLIN) and treatment (TRT) factors associated with Chronic Respiratory Infection Symptom Score (CRISS) symptom score ( - is an improvement). (B) Multivariate ORs and $95 \%$ Cls for factors associated with $<10 \%$ immediate response in $\mathrm{FEV}_{1}$ (L) during treatment. (C) Multivariate ORs and $95 \%$ Cls for factors associated with $<90 \%$ baseline (Base.) $\mathrm{FEV}_{1}$ recovery. (D) Multivariate HRs and $95 \% \mathrm{Cls}$ for factors associated with time to next intravenous antibiotic (abx). Factors with $\mathrm{p}<0.30$ were dropped from model and not estimated or plotted in figure. Base FEV $(<50 \%), \mathrm{FEV}_{1}$ per cent predicted at time of PEx; CFRD, cystic fibrosis-related diabetes; $\mathrm{FEV}_{1}$ Drop, $\mathrm{FEV}_{1}$ drop $\geq 10 \%$ presenting for PEx; MRSA, methicillin-resistant Staphylococcus aureus colonised at time of PEx; MRSA active drug, use of doxycycline, linezolid, minocycline, rifampin, tigecycline, vancomycin or trimethoprim/sulfamethoxazole; Oral or Inh, use of oral or inhaled antibiotics during treatment for $\mathrm{PEx} ; \mathrm{Pa}=P$. aeruginosa colonised at time of $\mathrm{PEx} ; 10-14$ days, total duration of intravenous antibiotic therapy compared with reference $<10$ days; $>14$ days, total duration of intravenous antibiotic therapy compared with reference $<10$ days.

\section{Short-term response and subsequent outcomes}

Change in symptom score was not associated with recovery of baseline lung function $(p=0.49)$ or time to next intravenous antibiotic $(p=0.69)$ when added to the multivariate logistic and Cox regression models presented in figure 3 and online

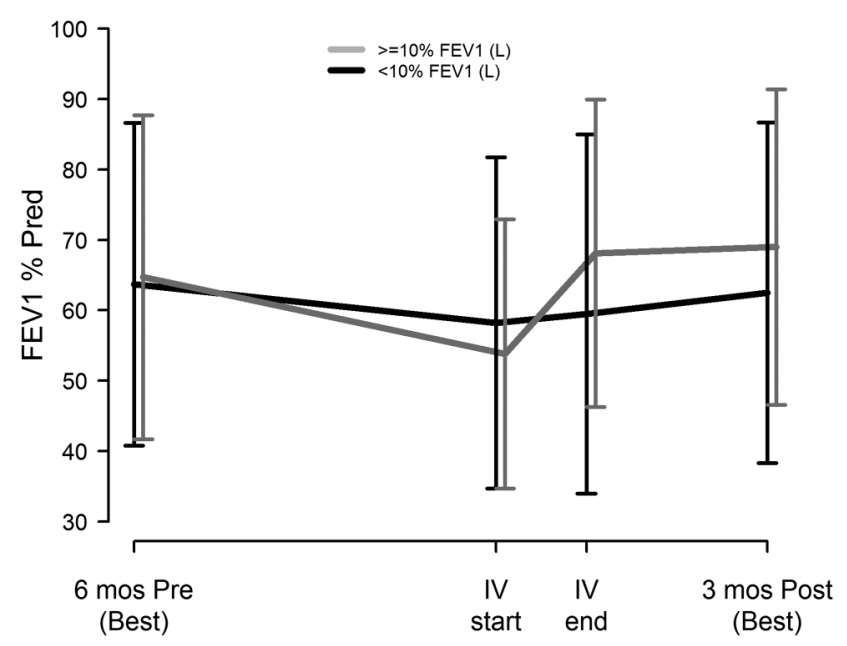

Figure 4 Lung function by immediate $\mathrm{FEV}_{1}$ response with treatment. $\mathrm{FEV}_{1} \%$ of predicted mean \pm 1 SD for participants with $<10 \%$ relative $\mathrm{FEV}_{1}(\mathrm{~L})$ response during pulmonary exacerbations (PEx) treatment (black lines, $n=35$ ) and participants $\geq 10 \%$ relative $\mathrm{FEV}_{1}(\mathrm{~L})$ response during treatment (gray lines, $n=67$ ): best during 6 months (mos) before study PEx, at time of intravenous (IV) initiation for PEx, at end of intravenous for PEx and best during 3 months after study PEx. supplementary table S1, respectively. Immediate non-response in $\mathrm{FEV}_{1}(<10 \%$ during treatment) significantly increased the odds of non-recovery of baseline $(\mathrm{OR}=7.8,95 \%$ CI 1.9 to 31.6 , $\mathrm{p}=0.004)$; no other covariates were significantly associated with post-PEx recovery when adjusted for short-term $\mathrm{FEV}_{1}$ response. Among those with immediate $\mathrm{FEV}_{1}$ response, 95\% recovered baseline by 3 months, whereas among those who had $<10 \%$ improvement during treatment, $73 \%$ recovered baseline. Figure 4 shows lung function by short-term $\mathrm{FEV}_{1}$ responder status.

In contradiction, short-term $\mathrm{FEV}_{1}$ non-response significantly decreased the risk of subsequent intravenous antibiotic event $(\mathrm{HR}=0.48,95 \% \mathrm{CI} 0.27$ to $0.85, \mathrm{p}=0.011)$ along with other significant factors that increased the risk: being a woman $(\mathrm{HR}=1.8,95 \% \mathrm{CI} 1.1$ to $3.1, \mathrm{p}=0.032)$, history of intravenous antibiotic event $(\mathrm{HR}=2.8,95 \% \mathrm{CI} 1.6$ to $4.8, \mathrm{p}<0.001)$ and low $\mathrm{FEV}_{1}$ at start of study PEx $(\mathrm{HR}=2.0$, 95\% CI 1.2 to 3.4, $\mathrm{p}=0.01$ ). Figure 5 shows the Kaplan-Meier curves to next intravenous antibiotic episode by short-term $\mathrm{FEV}_{1}$ responder status $(\mathrm{p}=0.07)$.

\section{DISCUSSION}

CF PEx are managed with a wide array of treatment regimens that may be based on patient or clinician preference, pathogen isolation, historical response or trajectory of response to treatment for the current PEx. In general, the short-term goals of treatment are to resolve symptoms and recover lost lung function, but there may also be long-term goals, such as preservation of lung function and prevention of subsequent acute events. We show, across multiple centres, that patient clinical characteristics and treatment factors that were associated with short-term 


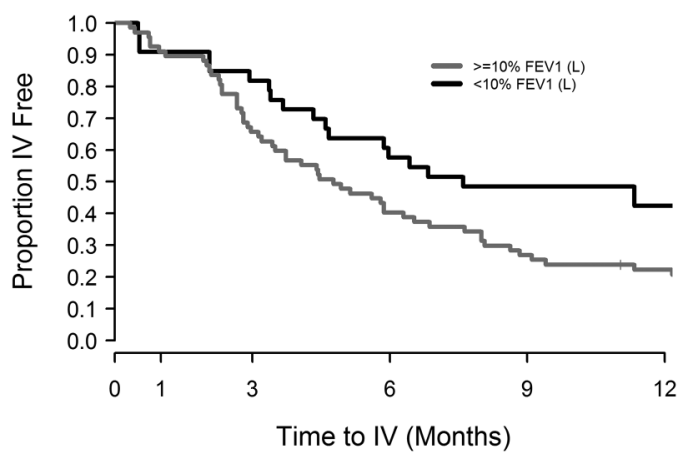

Figure 5 Kaplan-Meier survival curves for time to next intravenous (IV) antibiotic episode by immediate $\mathrm{FEV}_{1}$ response with treatment. Proportion intravenous antibiotic free by time (after study pulmonary exacerbations (PEx)) in participants with $<10 \%$ relative $\mathrm{FEV}_{1}(\mathrm{~L})$ response during PEx treatment (black lines, $n=35$ ) and those with $\geq 10 \%$ relative $\mathrm{FEV}_{1}(\mathrm{~L})$ response during treatment (gray lines, $\mathrm{n}=67$ ).

clinical improvement differed from those associated with subsequent lung function recovery and time to next acute event treated with intravenous antibiotics. In addition, immediate symptom resolution and lung function response did not have a clear relationship with longer term clinical outcomes.

To our knowledge, this is the first study to examine the multifactorial association between clinical and treatment features with patient-reported symptoms during a PEx. Improvement (ie, reduction in symptom score) was seen in nearly all patients; however, presence of MRSA was related to a diminished effect while steroids were significantly associated with a greater effect. This is contrary to a small randomised trial of steroids in children with CF that failed to see an effect of steroids on symptoms. ${ }^{29}$ Treating to improve patient signs and symptoms is a hallmark component of PEx management; however, it may not be indicative of downstream clinical outcomes. A CF symptom score during $\mathrm{PEx}^{30}$ has been associated with extending intravenous antibiotic duration ${ }^{17}$ and time to next PEx, ${ }^{31}$ but not when adjusting for other factors-similar to the findings of this study. The antibiotic course may be extended because of seeming lack of symptom improvement, but it is unclear if there are advantages to longer treatment that outweigh cost, time and potential toxicities.

The other common goal of PEx treatment is recovery of lost lung function. Nearly $90 \%$ of this sample recovered baseline lung function-higher than the $75 \%$ observed in the Registry from 2003 to $2006 .{ }^{4}$ We found that failure to improve $\mathrm{FEV}_{1}$ during treatment was associated with failure to recover pre-PEx lung function in the subsequent 3 months; however, in contradiction, short-term $\mathrm{FEV}_{1}$ non-response was associated with longer time to next intravenous antibiotic episode. Perhaps the patients with the highly variable, oscillating swings in lung function-large drops and big gains with treatment are easier to identify as requiring treatment for exacerbation, ${ }^{32}$ while those who are less responsive to intravenous antibiotics may be less likely to be admitted again for intravenous treatment when it did not appear to improve the patient's lung function. This analysis specifically examined the association of relative $\mathrm{FEV}_{1}$ improvement during treatment for PEx and subsequent 'baseline recovery' while adjusting for 'sick decline' and lung function at admission. An alternative short-term metric would be recovery of baseline lung function (best 6 months prior) at the end of treatment; however, such a measure would confound 'sick decline' rather than letting the analysis tease out any effect. Also, the calculation of baseline recovery includes the $\mathrm{FEV}_{1}$ measured at end of treatment (which is often the highest in the 3 months post-intravenous therapy); these measures of 'immediate response' and 'recovery of baseline' guaranteed mutually exclusive endpoints.

Extending the PEx-free interval is an important feature of CF disease management because these acute events have been shown to have long-term detrimental effects. ${ }^{1} 1833$ For this reason, time to next intravenous antibiotic course or PEx is a common and useful endpoint in clinical trials of chronic therapies ${ }^{34}$; however, it could be argued that because the majority of these events occur 4-6 months after treatment, they are too far downstream and confounded by factors not related to the acute management of the preceding PEx to serve as useful outcomes when studying success or failure PEx treatment regimens. Similarly, longterm lung function decline has been explored within the context of PEx; however, for studying PEx treatment regimens, an immediate outcome is necessary for both practicality and to reduce the influence of confounding factors. Several studies have shown the detrimental effect of exacerbation on long-term lung function in $\mathrm{CF}^{4}{ }^{18}$ These study data support those findings (history of intravenous antibiotics significantly increased the risk of failing to recover baseline lung function) and likely demonstrate that recurrent PEx events and underlying phenotype such as CFRD and MRSA colonisation are responsible for persistent respiratory decline more than a particular treatment regimen or response.

The inclusion criteria of this study required dual systemic, intravenous antibiotic therapy and thus likely excluded patients treated solely for MRSA infection (either because of exclusively oral or mono-therapeutic choices). Thereby, inference here applies only to CF exacerbations that required systemic dual therapy. The PEx guidelines found insufficient evidence to necessitate two antibiotics when $P$. aeruginosa is suspected, but neither was there support for less than two, and thus yielded to standard practice of two. ${ }^{13}$ P. aeruginosa prevalence in this study is consistent with the general CF population. ${ }^{6}$ PEx treatment guidelines also cited insufficient evidence of either benefit or harm from acute steroid use to treat CF exacerbations. ${ }^{13}$ While this study found some moderate benefit from steroid use, interpretations should be exercised with caution because of the potential for indication bias in a non-randomised study. The question of acute corticosteroids for treating CF PEx is of tremendous interest and would benefit from carefully controlled, randomised research.

There were limitations to our analysis of this observational study, one being that treatments may have been proxy for baseline clinical features or confounded with response. For example, duration was a treatment factor in this analysis; however, antibiotic regimens often changed and extended mid-course presumably for reasons of clinical non-response, therefore treatment was confounded with outcomes and has been treated as such in other studies. ${ }^{15}{ }^{17}$ Additions or changes to the treatment may have been related to microbial susceptibility testing or convenience/preference. For these reasons, it is challenging to interpret the relationship between treatment factors and outcomes. This multisite paediatric and adult study augmented with CF NPR data yields generalisable findings for short-term and long-term PEx outcomes-perhaps at the expense of increased heterogeneity resulting from site variability, irregular spirometry timing and unmonitored supplemental data. Lastly, all our statistical models were estimable and coefficients were stable; however, the sample size is moderately small and no adjustments were made for multiple comparisons, therefore associations and $\mathrm{p}$ values should be interpreted with caution. 
Symptom resolution and immediate improvement in $\mathrm{FEV}_{1}$ are meaningful measures of acute PEx therapy, and we show them to be more associated with treatment features than long-term measures. Short-term non-response in symptoms or lung function during treatment was not clearly related with subsequent PEx; however, immediate $\mathrm{FEV}_{1}$ response does appear to be associated with recovery of baseline lung function. Also, some of the contradictory results we observed support the use of a composite response $\mathrm{e}^{15}$ of short-term clinical features to serve as a trial outcome (eg, lung function or symptom improvement without additional intravenous antibiotics within a month of the initial treatment). A larger cohort may support or refute our results, while randomised controlled studies of PEx treatment will ultimately produce the evidence necessary to improve the overall well-being of patients with CF.

\section{Author affiliations}

${ }^{1}$ Cystic Fibrosis Foundation Therapeutics Development Network Coordinating Center, Seattle Children's Research Institute, Seattle, Washington, USA

${ }^{2}$ Department of Pediatrics, University of Washington, School of Medicine, Seattle, Washington, USA

${ }^{3}$ Division of Pulmonary and Critical Care Medicine, University of Washington School of Medicine, Seattle, Washington, USA

${ }^{4}$ Department of Pediatrics, University of Colorado School of Medicine and Children's Hospital Colorado, Aurora, Colorado, USA

${ }^{5}$ Department of Pediatrics, University of Wisconsin School of Medicine and Public Health, Madison, Wisconsin, USA

${ }^{6}$ Cystic Fibrosis Foundation, Bethesda, Maryland, USA

7 Department of Medicine and Pediatrics, Medical University of South Carolina, Charleston, South Carolina, USA

Correction notice This article has been corrected since it was published Online First. The provenance and peer review statement has been corrected.

Acknowledgements We would like to thank the Cystic Fibrosis Foundation for the use of CF Foundation Patient Registry data. Additionally, we would like to thank the patients, care providers and clinic coordinators at CF Centers throughout the USA for their contributions. We also recognise the three anonymous peer reviewers whose suggestions greatly improved this manuscript.

Contributors SLH, SDS and PAF designed the study, SLH, VT, SDS, CHG, DBS $\mathrm{BCM}$ and PAF contributed substantially to the data analysis and interpretation, and the writing of the manuscript.

Funding This research was supported by Cystic Fibrosis Foundation Therapeutics (SAGEL07B0, SAGEL11CSO, HAMBLE10A0, HELTSH13A0), the National Institutes of Health (NIDDK P30 DK089507, KL2 TR000428), the SCTR Institute at the Medical University of South Carolina (NIH UL1 TR000062), NCATS Colorado CTSI (NIH UL1 TR000154) and the University of Wisconsin-Madison ICTR (NIH UL1 TR000427).

Competing interests None declared.

Patient consent Obtained

Ethics approval All participating site Institutional Review Boards and the primary site of analysis: Seattle Children's Institutional Review Board.

Provenance and peer review Not commissioned; externally peer reviewed.

Data sharing statement Study data can be requested through SDS or the Cystic Fibrosis Foundation Therapeutics Development Network.

\section{REFERENCES}

1 Liou TG, Adler FR, Fitzsimmons SC, et al. Predictive 5-year survivorship model of cystic fibrosis. Am J Epidemiol 2001;153:345-52.

2 de Boer $\mathrm{K}$, Vandemheen $\mathrm{KL}$, Tullis $\mathrm{E}$, et al. Exacerbation frequency and clinical outcomes in adult patients with cystic fibrosis. Thorax 2011;66:680-5.

3 Sawicki GS, Rasouliyan L, McMullen AH, et al. Longitudinal assessment of health-related quality of life in an observational cohort of patients with cystic fibrosis. Pediatr Pulmonol 2011:46:36-44.

4 Sanders DB, Bittner RC, Rosenfeld M, et al. Failure to recover to baseline pulmonary function after cystic fibrosis pulmonary exacerbation. Am J Respir Crit Care Med 2010;182:627-32.

5 Briesacher BA, Quittner AL, Fouayzi $\mathrm{H}$, et al. Nationwide trends in the medical care costs of privately insured patients with cystic fibrosis (CF), 2001-2007. Pediatr Pulmonol 2011;46:770-6.

6 Cystic Fibrosis Foundation Patient Registry: Annual Data Report 2012. Bethesda, MD: Cystic Fibrosis Foundation, 2012.
7 Kraynack NC, Gothard MD, Falletta LM, et al. Approach to treating cystic fibrosis pulmonary exacerbations varies widely across US CF care centers. Pediatr Pulmonol 2011;46:870-81

8 Wagener JS, Rasouliyan L, VanDevanter DR, et al. Oral, inhaled, and intravenous antibiotic choice for treating pulmonary exacerbations in cystic fibrosis. Pediatr Pulmonol 2013;48:666-73.

9 Proesmans M, Heyns L, Moons $\mathrm{P}$, et al. Real life evaluation of intravenous antibiotic treatment in a paediatric cystic fibrosis centre: outcome of home therapy is not inferior. Respir Med 2009;103:244-50.

10 Thornton J, Elliott R, Tully MP, et al. Long term clinical outcome of home and hospital intravenous antibiotic treatment in adults with cystic fibrosis. Thorax 2004:59:242-6.

11 Collaco JM, Green DM, Cutting GR, et al. Location and duration of treatment of cystic fibrosis respiratory exacerbations do not affect outcomes. Am I Respir Crit Care Med 2010;182:1137-43.

12 Wolter JM, Bowler SD, Nolan PJ, et al. Home intravenous therapy in cystic fibrosis: a prospective randomized trial examining clinical, quality of life and cost aspects. Eur Respir J 1997;10:896-900.

13 Flume PA, Mogayzel PJ Jr, Robinson KA, et al. Cystic fibrosis pulmonary guidelines: treatment of pulmonary exacerbations. Am I Respir Crit Care Med 2009;180:802-8

14 Blumer JL, Saiman L, Konstan MW, et al. The efficacy and safety of meropenem and tobramycin vs ceftazidime and tobramycin in the treatment of acute pulmonary exacerbations in patients with cystic fibrosis. Chest 2005;128: $2336-46$

15 Parkins MD, Rendall JC, Elborn JS. Incidence and risk factors for pulmonary exacerbation treatment failures in patients with cystic fibrosis chronically infected with Pseudomonas aeruginosa. Chest 2012;141:485-93.

16 VanDevanter DR, O'Riordan MA, Blumer JL, et al. Assessing time to pulmonary function benefit following antibiotic treatment of acute cystic fibrosis exacerbations. Respir Res 2010;11:137.

17 Sequeiros IM, Jarad NA. Extending the course of intravenous antibiotics in adult patients with cystic fibrosis with acute pulmonary exacerbations. Chron Respir Dis 2012;9:213-20.

18 Waters V, Stanojevic S, Atenafu EG, et al. Effect of pulmonary exacerbations on long-term lung function decline in cystic fibrosis. Eur Respir J 2012;40:61-6.

19 Stenbit AE, Flume PA. Pulmonary exacerbations in cystic fibrosis. Curr Opin Pulm Med 2011;17:442-7.

20 Clinical practice guidelines for cystic fibrosis. Bethesda, MD: Cystic Fibrosis Foundation, 1997. Appendix VIII, Table 7.

21 Sagel SD, Thompson V, Chmiel JF, et al. Effect of Treatment of Cystic Fibrosis Pulmonary Exacerbations on Systemic Inflammation. Ann Am Thorac Soc 2015;12:708-17.

22 [No authors listed]. Standardization of Spirometry, 1994 Update. American Thoracic Society. Am J Respir Crit Care Med 1995;152:1107-36.

23 Hankinson JL, Odencrantz JR, Fedan KB. Spirometric reference values from a sample of the general U.S. population. Am J Respir Crit Care Med 1999:159:179-87.

24 Wang X, Dockery DW, Wypij D, et al. Pulmonary function between 6 and 18 years of age. Pediatr Pulmonol 1993;15:75-88.

25 Goss CH, Edwards TC, Ramsey BW, et al. Patient-reported respiratory symptoms in cystic fibrosis. J Cyst Fibros 2009;8:245-52

26 Rosenfeld M, Emerson J, Williams-Warren J, et al. Defining a pulmonary exacerbation in cystic fibrosis. J Pediatr 2001;139:359-65.

27 Goss $\mathrm{CH}$, Caldwell E, Gries KS, et al. Validation of a novel patient-reported respiratory symptoms instrument in cystic fibrosis: CFRSD-CRISS. Pediatr Pulmonol 2013;S36:1.

28 Hosmer DW, Lemeshow S. Applied logistic regression. 2nd edn. New York, NY: Wiley, 2000:91-142.

29 Dovey M, Aitken ML, Emerson J, et al. Oral corticosteroid therapy in cystic fibrosis patients hospitalized for pulmonary exacerbation: a pilot study. Chest 2007;132:1212-18.

30 Jarad NA, Sequeiros IM. A novel respiratory symptom scoring system for CF pulmonary exacerbations. QJM 2012;105:137-43.

31 Sequeiros IM, Jarad N. Factors associated with a shorter time until the next pulmonary exacerbation in adult patients with cystic fibrosis. Chron Respir Dis 2012;9:9-16.

32 Morgan WJ, Wagener JS, Yegin A, et al. Probability of treatment following acute decline in lung function in children with cystic fibrosis is related to baseline pulmonary function. J Pediatr 2013;163:1152-7.e2.

33 Goss $\mathrm{CH}$, Burns JL. Exacerbations in cystic fibrosis. 1: Epidemiology and pathogenesis. Thorax 2007;62:360-7.

34 McCoy KS, Quittner AL, Oermann CM, et al. Inhaled aztreonam lysine for chronic airway Pseudomonas aeruginosa in cystic fibrosis. Am J Respir Crit Care Med 2008;178:921-8

35 Saiman L, Marshall BC, Mayer-Hamblett N, et al. Azithromycin in patients with cystic fibrosis chronically infected with Pseudomonas aeruginosa: a randomized controlled trial. JAMA 2003;290:1749-56. 